\title{
Estudo Exploratório sobre o Desenvolvimento de Talentos entre os Kayabi
}

\author{
Jane Farias Chagas-Ferreira* \\ Universidade de Brasília - UnB, Brasília, DF, Brasil \\ ORCID: https://orcid.org/0000-0002-7087-8738
}

\section{RESUMO}

Este estudo exploratório teve como objetivo identificar quais são os talentos (habilidades, saberes ou técnicas) reconhecidos pela comunidade Kayabi e como ela se organiza para a promoção e desenvolvimento desses talentos. Participaram da pesquisa quatro pessoas, todas envolvidas em atividades de ensino e liderança na comunidade Kayabi, sendo três delas nativas. Os dados foram analisados por procedimento construtivo-interpretativo e coletados por meio de análise documental, questionário sociodemográfico e entrevista. As habilidades identificadas pelos Kayabi tinham vínculo com suas tradições ancestrais e eram associadas às áreas artística, linguística e política. As pessoas talentosas eram denominadas por especialistas. Os especialistas desenvolviam suas habilidades pela observação, imitação e orientação de outros especialistas e tinham a responsabilidade de transmitir os seus conhecimentos e técnicas para os mais jovens. A família foi reconhecida como a principal promotora e provedora dos recursos necessários ao desenvolvimento dos talentos. Entre os desafios apontados destacaram-se a escassez de matéria prima ou falta de recursos financeiros e a inexistência de local apropriado para a produção artesanal. Para pesquisas futuras recomenda-se o estudo das interrelações entre os processos individuais e comunitários em que esses talentos emergem e se desenvolvem.

Palavras-chave: desenvolvimento de talentos, superdotação, Kayabi, povos indígenas.

\section{Talent Development Among the Kayabi: An Exploratory Study}

\begin{abstract}
This exploratory study aims to identify which are the talents (skills, knowledge, or techniques) recognized by the Kayabi community and how they are organized for the promotion and development of these talents. Four people participated in the research, all involved in teaching and leadership activities among the Kayabi, three of whom are native. Data were analyzed by constructive-interpretative procedure and collected through document analysis, sociodemographic questionnaire, and interview. The skills identified by Kayabi were linked to their ancestral traditions and associated with the artistic, linguistic, and political fields. Talented people were called experts. Experts developed their skills by observing, imitating, and following the instructions of other experts, and were responsible for sharing their knowledge and techniques to young people. The family was seen as the leading promoter and provider of the resources needed for talent development. Among the challenges
\end{abstract}


highlighted were the lack of raw materials and financial resources and the lack of a suitable place for artisanal production. For future research, it is recommended to study the interrelationships between individual and community processes in which these talents emerge and develop.

Keywords: talent development, giftedness, Kayabi, indigenous people.

\section{Desarrollo del Talento entre los Kayabi: Un Estudio Exploratorio}

\section{RESUMEN}

Este estudio exploratorio tuvo el objetivo de identificar cuáles son los talentos (habilidades, conocimientos o técnicas) reconocidos por la comunidad Kayabi y cómo se organiza para la promoción y el desarrollo de estos talentos. Cuatro personas participaron en la investigación, todas involucradas en actividades de enseñanza y liderazgo en la comunidad Kayabi, tres de los cuales son nativos. Los datos se analizaron mediante procedimiento constructivointerpretativo y se recopilaron mediante análisis documental, cuestionario sociodemográfico y entrevista. Las habilidades identificadas estaban vinculadas a sus tradiciones ancestrales y asociadas con las áreas artísticas, lingüísticas y políticas. Las personas con talento se llamaban expertos. Los expertos desarrollaron sus habilidades observando, imitando y guiando a otros y tenían la responsabilidad de transmitir sus conocimientos y técnicas a los más pequeños. La familia fue reconocida como la principal promotora y proveedora de los recursos necesarios para el desarrollo de talentos. Entre los desafíos destacados se encuentran la escasez de materias primas, la falta de recursos financieros y la falta de un lugar apropiado para la producción artesanal. Para futuras investigaciones, se recomienda estudiar las interrelaciones entre los procesos individuales y comunitarios en los que estos talentos emergen y se desarrollan.

Palabras clave: desarrollo de talento, superdotación, Kayabi, pueblos indígenas.

Há evidências empíricas de que pelo menos $10 \%$ de uma população possui traços de superdotação (Renzulli \& Reis, 2014). Obviamente, identificar esse contingente requer a elaboração de políticas públicas abrangentes e o planejamento de oportunidades de atendimento igualmente amplas e diversas. No Brasil, o número de crianças e adolescentes historicamente atendidos em Atendimento Educacional Especializado para Superdotados ao longo das últimas décadas está bem abaixo da média do que é indicado na literatura entre 5 a $20 \%$ dos estudantes (Weschler \& Fleith, 2017). Esse número é ainda mais inexpressivo ou inexistente quando se busca algum registro ou pesquisas acerca do atendimento de indígenas, ciganos, quilombolas ou assentados rurais. Esses são talentos invisíveis e desperdiçados. Fato que pode contribuir com a extinção de parte do patrimônio imaterial dessas comunidades 
tradicionais, ao mesmo tempo em que evidencia a resistência e resiliência desses povos na manutenção de suas tradições. Tradições que demonstram forte ligação com o território de seus ancestrais, com seus sistemas de produção e processos transgeracionais marcados pela oralidade.

O conjunto de elementos que definem talento ou superdotação pode ser distinto para cada grupo social e essa definição terá implicações na maneira como essa comunidade se organizará para promover ou não o desenvolvimento das potencialidades e habilidades reconhecidas e valorizadas (Sternberg, Jarvin, \& Grigorenko, 2011). Soma-se a essa constatação, o entendimento de que a cultura está em constante mudança, o que envolve um processo dinâmico de criação, metamorfose e recriação de conceitos. Sendo assim, corroboramos o argumento de Becker e Milon (2012) ao considerarem o quanto é desafiador compreender o modo de vida indígena, seus valores e cosmovisão numa perspectiva do desenvolvimento de talentos.

Siegle et al. (2016) chamam a atenção de que existem outras barreiras que podem influenciar de forma negativa o processo de identificação de talentos em populações de superdotados de grupos minoritários ou comunidades tradicionais (populações rurais, negros, imigrantes, indígenas, entre outros) e que acabam por explicar a escassa ou inexistente oferta de serviços ou programas que atendam a esses grupos. Entre as principais barreiras apontadas destacam-se: (a) os currículos fortemente orientados para o desenvolvimento de habilidades acadêmicas; (b) processos de identificação padronizados que utilizam instrumentos que não são validados para abrangerem as características socio-histórico-culturais de grupos minoritários; (c) a utilização de medidas e instrumentos que exigem a leitura ou a comunicação escrita; (d) acesso a oportunidade de atendimento centrado na mediação, indicação e nomeação feita pela escola e por professores; (e) disseminação de crenças e valores dominantes que desqualificam aspectos socioculturais de outras etnias ou grupos sociais e (f) escasso acesso a oportunidades de atendimento educacional.

Encontramos na literatura brasileira dois estudos acerca do talento entre indígenas, realizados por Becker, Nino e Weigel (2009) e Becker e Milon (2012). Becker, Nino e Weigel (2009) realizaram uma pesquisa-ação com 12 professores da etnia Sateré-Mawé que frequentaram curso de formação para a Educação Indígena. Os resultados demonstraram que os professores reconheciam como possível talento a pajelança, o canto ritual, a rapidez para aprender e as habilidades de desenho e pintura.

Becker e Milon (2012) implementaram um estudo descritivo exploratório de caráter etnográfico com professores e estudantes da etnia Mura. Foram utilizados como instrumentos 
(1) a observação participante; (2) o diálogo intercultural, que se constitui em um processo interativo de troca de ideias a partir de indagações que permitem aos participantes expressassem espontaneamente suas ideias; e (3) questionário com perguntas abertas e fechadas. A hermenêutica diatópica, que implica na colaboração intercultural e construção de sentidos aplicado ao conceito de pessoas talentosas, foi empregada na análise de dados. Por meio de idas ao campo, foram identificados pelos professores utilizando-se de uma lista de características de pessoas talentosas nas áreas intelectual-acadêmica, lideranças, artes e psicomotora, treze estudantes indígenas da etnia Mura. Os professores entendiam o talento como algo nato que precisa ser estimulado e consideravam que havia uma multiplicidade de potencialidades humanas. Na percepção destes, o principal atributo da pessoa talentosa seria a satisfação demonstrada ao fazer algo de seu interesse.

A maioria dos estudantes indicados pelos professores eram da área intelectualacadêmica, seguidos dos da área de artes: desenho, escultura e canto. As autoras indicaram que o Modelo dos Três Anéis elaborado por Renzulli (Renzulli \& Reis, 2014), empregado na maior parte dos serviços educacionais destinados ao atendimento de superdotados em nosso país, contribui para a indicação de jovens talentos indígenas. Este modelo concebe a superdotação como um conjunto de três fatores: habilidades acima da média, criatividade e envolvimento com a tarefa. Por outro lado, recomendam que os processos de identificação formais sejam repensados, uma vez que os instrumentos e procedimentos utilizados na maioria desses serviços desconsideram a diversidade cultural, os modos de pensar, viver e explicar o mundo de comunidades tradicionais.

Com relação à expressão criativa entre indígenas brasileiros, Alencar, Braga, Prado e Chagas-Ferreira (2015) e Oliveira (2017) destacam alguns aparatos listados com frequência na literatura como a pintura corporal; o uso de ornamentos coloridos; o canto; a dança; a elaboração de artefatos de cerâmica, palha e madeira; a confecção de ferramentas e armas, os jogos, as brincadeiras e brinquedos utilizados por crianças e a contação de histórias. Entre as habilidades são reconhecidas a força física; as habilidades relacionadas à caça, pesca e plantio; o conhecimento sobre plantas medicinais; a comunicação com os ancestrais, os espíritos e a natureza; a maneira como constroem suas armas e armadilhas; a arquitetura de suas casas; os trançados dos utensílios e os instrumentos musicais (Alencar, et al., 2015; Oliveira, 2017). Esses saberes, habilidades e produtos são fruto da prática, observação e instrução dos mais experientes (Lima \& Sato, 2011).

Bampil e Diel (2017), denunciam que ainda persiste um olhar discriminatório e etnocêntrico com relação à população e à produção criativa indígena. Essa percepção 
dissemina ideias estereotipadas que demonstram o desconhecimento sobre a diversidade dos povos indígenas no Brasil e revelam certa desvalorização de seus modos de vida. Essa postura acaba por tornar invisível seus talentos, potencialidades e saberes. Resultados de estudo realizado por esses autores demonstraram a necessidade de se construir redes de interlocução como estratégia de diminuir os preconceitos e valorizar a cultura indígena.

Diante do exposto, esta pesquisa exploratória teve como objetivo identificar quais são os talentos (habilidades, saberes ou técnicas) reconhecidos pela comunidade Kayabi do Rio Teles e como ela se organiza para a promoção e desenvolvimento desses talentos.

\section{Kayabi: História e Cultura}

O povo Kayabi faz parte da filiação linguística Tupi-Guarani e até meados do século XX habitava as margens dos rios Verde, Arinos e Peixes, nos estados do Mato Grosso e Pará. Com a ocupação de suas terras nos anos 1950 por fazendeiros e seringueiros, por conta do crescimento da indústria de borracha, boa parte de sua população foi transferida para o Parque Nacional do Xingu (MT). Após a demarcação de suas terras, em 2013, os Kayabi retornaram à terra sagrada de seus ancestrais e deram início ao fortalecimento de suas tradições e ao resgate de sua cultura e língua (Alcântara, 2015; Brunet, 2018; Guimarães, 2017; Pagliaro, 2010). Atualmente, grande parte do povo Kayabi habita o norte do Mato Grosso e o sul do Pará, às margens dos rios Teles Pires, Peixes e Kururuzinho. De acordo com o último Censo de 2010, 1.814 pessoas se autodeclararam como Kayabi, no entanto dados mais recentes dão conta de um contingente em torno de 2.202 pessoas (Alcântara, 2015).

Encontramos na literatura dados sobre a importância dos grafismos e da música, especialmente do canto e da dança, como patrimônio imaterial do povo Kayabi. Esse patrimônio envolve aspectos da sua cosmologia em estreita relação com a natureza, cujos aspectos simbólicos são repassados de geração em geração por meio de tradição oral (Carvalho \& Ferreira, 2017; Guimarães, 2017). As pinturas e manifestações gráficas fazem parte do dia a dia, constituindo-se como um emblema étnico ou identidade que os distinguem de outros povos. Os grafismos e pinturas se caracterizam por complexos padrões com linhas retas e geométricas que remetem à mitologia Kayabi (animais sobrenaturais e seres da floresta, associação entre o natural e o espiritual) e estão presentes nos seus ritos, nos objetos cotidianos, na tecelagem, cestaria e ornamentos (Athayde, Silva-Lugo, Schmink, Kaiabi, \& Heckenberger, 2017; Bampil \& Diel, 2017; Lima \& Sato, 2011). 
Para a pintura do corpo, eles utilizam a tinta do jenipapo ou urucum e usam uma técnica muito parecida com a que os tatuadores utilizam de furar a pele e introduzir nela a tintura. Essas "tatuagens" podem simbolizar seus próprios nomes, os nomes dos guerreiros que matavam (no passado) e hoje, estão relacionadas com a luta por direitos e resistência cultural. Os Kayabi ganham novos nomes ao longo de suas vidas, a depender de eventos rituais e de passagem como: a entrada na vida adulta, o nascimento de um filho, casamento, entre outros (Carvalho \& Ferreira, 2017).

$\mathrm{O}$ artesanato e os artefatos são produzidos em função de demandas da própria comunidade. Os homens, tradicionalmente, se dedicam à fabricação de arcos, flechas e cocares, enquanto as mulheres tecem as redes, as roupas e os adereços. No entanto, Athayde et al. (2017) relatam evidências de inovação nos modos de criação e meios de transmissão do conhecimento como: o intercâmbio de técnicas entre os sexos; o emprego de técnicas retiradas de outras culturas; a experimentação; o emprego de novas matérias-primas na confecção de artefatos e a transferência de grafismos da pintura corporal para objetos esculpidos, cestaria e adereços.

Em suma, tanto a produção artística quanto a história comunitária estão interconectadas com as características ambientais da terra onde habitam. Na cosmologia Kayabi, o território é vivo e provedor não somente dos recursos necessários para a subsistência e a produção cultural, mas também para construção de um senso de pertencimento que unifica os sentidos e significados e dá coerência às suas trajetórias e estilo de vida. Athayde et al. (2017) corroboram esse entendimento, observando que os atos de criação desses artefatos estão ligados ao desenvolvimento simbólico, de forma que estão vivos tanto os objetos produzidos quanto os materiais utilizados. Nesse sentido, os seres vivos se transmutam em objetos e vice-versa: as plantas que antes eram comida se transformam em cestos que carregam os alimentos; os jovens passam a ser adultos após os rituais em que seus corpos são tatuados; e o homem comum passar a ser sobrenatural pela utilização de máscaras e objetos rituais. Nesse processo, o xamã, o artista, o ancião e o cientista Kayabi se fundem por meio dos ritos, dos saberes compartilhados e das práticas de vida. Os artefatos, os ritos e o estilo de vida formam um conjunto indissociável como patrimônio imaterial dos Kayabi.

Alguns estudiosos revelam a preocupação latente com patrimônio imaterial dos povos indígenas em geral, e em especial com os Kayabi (Alcântara, 2015; Athayde et al., 2017; Ferreira, 2014; Mori, Cruz, \& Quintino, 2017). Isto se deve a dois fatores: (1) esses povos possuem uma tradição oral centrada no papel dos anciãos, como guardiões da cultura e (2) há uma tendência entre os indivíduos mais jovens de abandonarem as tradições - histórias, 
costumes, valores e práticas - de seus antepassados, com isso interrompendo o fluxo da transmissão oral entre as gerações. Esses processos demonstram o risco de extinção das práticas e de aspectos relevantes da identidade dessas comunidades. A morte de um ancião representa o desaparecimento de um acervo cultural de inestimável valor. Com isso, várias técnicas de registro audiovisual (catálogos fotográficos, vídeos, documentários) têm sido empregadas na tentativa de preservação dos processos de produção da arte Kayabi, de sua cultura e língua (Athayde et al., 2017).

Esses autores reconhecem a importância da Educação Indígena e Educação Escolar Indígena adequada à diversidade cultural, que promova a preservação do patrimônio material e imaterial dos povos indígenas, sua valorização pelos mais jovens e o desenvolvimento das potencialidades dessas comunidades (Alcântara, 2015; Ferreira, 2014; Mori, Cruz, \& Quintino, 2017). A Educação Escolar Indígena tem dois principais objetivos voltados a proporcionar (1) a recuperação das memórias históricas de cada povo, a reafirmação de suas identidades étnicas e a valorização de suas línguas e ciências e (2) o acesso à informações, conhecimento técnico e científico das demais sociedades indígenas e não-indígenas (Brasil, 2002, 2012; Mori, Cruz, \& Quintino, 2017). Também são apontados alguns desafios para a sua implantação, como: (a) organização curricular que leve em consideração a interculturalidade, diversidade e bilinguismo; (b) produção de material didático-pedagógico específico; e (c) formação de professores (Ferreira, 2014; Silva \& Ferreira, 2016). Nesse sentido, Alcântara (2015) destaca princípios a serem observados como: a transcendência entre o natural e o sobrenatural, a cooperação e intercâmbio, os valores próprios das sociedades orais, a reciprocidade, a formação integral de crianças e jovens e as "experiências cognitivas e afetivas com seus múltiplos significados econômicos, sociais, técnicos, rituais e cosmológicos" (Alcântara, 2015, p. 45).

Nas comunidades Kayabi, de acordo com Ferreira (2014) e Silva e Ferreira (2016), existem escolas cuja função precípua é formar estudantes críticos, criativos, independentes e que tenham como defender seus direitos, preservar suas memórias, fortalecer sua identidade e fazer com que seu território seja respeitado. Esses princípios fortalecem e estimulam a representação de jovens Kayabi em diferentes movimentos, associações e projetos

Apesar dos avanços na legislação e nas políticas públicas, a população indígena, como acontece em outros países, continua a ocupar lugar entre os grupos historicamente em situação de desvantagem econômica e com escasso acesso à educação de qualidade (Siegle et al., 2016; Silva \& Ferreira, 2016). Com isso, tornam-se relevantes as iniciativas para o reconhecimento dos talentos entre esses povos, como forma de contribuir para a preservação 
da biodiversidade, de seu patrimônio imaterial e para o seu desenvolvimento de forma sustentável (Athayde et al., 2017).

\section{Método}

Este estudo tem um delineamento qualitativo exploratório e descritivo. As pesquisas exploratórias visam a compreensão mais aprofundada de um fenômeno e a descrição de características de uma população (Breakwell, Fife-Schaw, Hammond \& Smith, 2010).

\section{Participantes}

Participaram desta pesquisa quatro pessoas envolvidas em projetos de ensino e liderança em uma aldeia Kayabi que vivia às margens do Rio Teles Pires. Todos eram casados e terão os seus nomes mantidos em sigilo por questões éticas. Dois participantes eram professores, do gênero masculino (K1 e K2) e tinham, respectivamente, 23 e 41 anos. K2 era líder de uma associação indígena. Entre as mulheres, uma era agente de saúde, sendo indicada pelos participantes como uma das especialistas da comunidade e como parte da liderança feminina e tinha 31 anos (K3). A outra participante era pedagoga, trabalhava como assessora voluntária na escola indígena da comunidade por 31 anos e tinha 57 anos (K4). Três participantes eram indígenas e moravam na mesma comunidade há mais de 10 anos.

\section{Instrumentos}

Análise Documental. Foi realizada a partir de buscas no Google Acadêmico, portal da CAPES e sites organizações não-governamentais e de órgãos oficiais do governo brasileiro. Foram compilados artigos, dissertações de mestrado, publicações e dados relevantes para o delineamento de aspectos macrossistêmicos acerca do povo Kayabi - valores, crenças, tradições e manifestações culturais entre outros, que auxiliaram na revisão de literatura.

Questionário Sociodemográfico. O Questionário visava coletar dados sobre a idade, nível de escolaridade, sexo, profissão, residência, estado civil e papel de liderança na comunidade.

Roteiro de Entrevista Semiestruturado. O roteiro de entrevista continha quatro conjuntos de perguntas abertas relacionadas a: (1) cosmovisão sobre o talento; (2) identificação de características de pessoas talentosas na comunidade; (3) descrição de 
estratégias ou recursos comunitários para o desenvolvimento dos talentos; e (4) desafios a serem superados para o desenvolvimento das potencialidades que existem na comunidade. Alguns exemplos de perguntas são: $\mathrm{Na}$ sua comunidade, que tipo de habilidades são valorizadas? Como as atividades realizadas na comunidade podem ajudar essas pessoas a terem os seus talentos desenvolvidos? Quais são os principais valores, recursos e potenciais que a sua comunidade possui?

\section{Procedimentos de Coleta de Dados}

Os participantes foram convidados a colaborar com a pesquisa pela pesquisadora ou por líderes da comunidade. Todos assinaram o Termo de Consentimento Livre e Esclarecido, após apresentação dos objetivos do estudo e antes de preencheram o questionário e participarem das entrevistas. As entrevistas foram realizadas individualmente em espaço comunitário na aldeia, durante os meses de março e junho de 2019 e tiveram uma duração média de 30 minutos. Após a análise dos dados, foi realizado contato com um dos participantes para obter feedback sobre as interpretações elaboradas. Essa pesquisa seguiu todos os procedimentos éticos e foi autorizada pelo cacique da comunidade.

\section{Análise dos Dados}

Os dados foram analisados por meio de procedimentos qualitativos, utilizando-se como procedimento de análise os sentidos evidenciados tomando como base a Epistemologia Qualitativa. De acordo com González-Rey (2011), o pesquisador constrói e reconstrói representações teóricas acerca do fenômeno estudado ao longo do processo de pesquisa. Nesse tipo de análise, destacam-se o caráter construtivo-interpretativo da produção do conhecimento; o processo de comunicação e o diálogo como instância de produção do conhecimento científico.

\section{Resultados}

As pessoas talentosas entre os Kayabi são reconhecidas pelas suas habilidades artísticas, linguísticas, de liderança ou de manejo de aspectos da vida comunitária (solução de conflitos e problemas, relações interpessoais) e são chamadas de especialistas. Os especialistas desenvolvem as suas habilidades a partir da orientação de outros especialistas em 
sua área, por meio da observação e reprodução. Esse fato é ilustrado por meio do relato de K4 acerca de uma senhora da comunidade e seu marido:

Ela me disse que não foi através de curso, mas observando pessoas que faziam. Ela também busca na internet modelos e reproduz. O esposo desta senhora, que também estudou fora da aldeia, aprendeu por observação a fazer cestos, cocares e bordunas (..) também aprendeu o ofício de pedreiro e a tocar violão.

Apesar de não valorizarem o destaque pessoal, os especialistas costumam ser bem vistos e respeitados dentro e fora de sua comunidade local. Esse respeito pode, inclusive, ser estendido à sua família. De acordo com a pedagoga K4: "Pessoas com habilidade especial são sempre lembradas e procuradas pelos demais membros do grupo, seja para o aprendizado bem como para encomendar algum artesanato. De certa forma, esta procura é uma forma de reconhecimento".

Os ensinamentos de um especialista são preciosos para aqueles que querem aprender as mesmas habilidades, sendo esse processo de aprendizagem inicial realizado dentro da própria família. Alguns especialistas podem exercer liderança na comunidade, principalmente se forem anciãos. Eles estão alinhados com as crenças e valores da comunidade, trabalham voluntariamente na formação de outros e são valorizados por sua disposição em ajudar. $\mathrm{Na}$ percepção de K4: “A contribuição desses especialistas, ou pessoas habilidosas, está no fato delas contribuírem para a valorização da expressão artística e cultural do povo”.

Os especialistas servem de modelo para crianças e mais jovens e colaboram com a sua formação por meio da troca de saberes. Nesse sentido, o professor K2 salientou que todos ouvem e procuram reservar um tempo para aprender com essas pessoas. Eles serão lembrados pelo seu povo, em virtude de seu legado e colaboração. Para os Kayabi, “a colaboração, a cooperação e o compartilhar são muito valorizados e incentivados desde criança. Quem não colabora, se isola. Quem não costuma ou gosta de cooperar é considerada uma pessoa sovina e não muito digna de confiança” (K4). Esta percepção era compartilhada por todos os participantes.

Em síntese, os especialistas possuem habilidades acima da média e atuam como tutores ou mentores. Eles contribuem com a preservação da identidade cultural de seu povo, dominam técnicas e conhecimentos específicos. No caso dos líderes/anciãos, possuem o papel de guardiões das tradições ancestrais e da história do seu povo. Essas pessoas têm a responsabilidade de transmitir aos mais jovens o seu conhecimento, servindo-lhes de modelo. 
Essa transmissão ocorre no seio da família extensa, sendo por ela apoiada como provimento dos recursos necessários para a produção.

As habilidades reconhecidas tinham estreita ligação com a cultura Kayabi que ocupava um aspecto central no desenvolvimento das habilidades em termos de caça, pesca, dinâmica da vida doméstica. Esses valores culturais eram tensionados pela necessidade de novos conhecimentos para aperfeiçoamento técnico, mas também pelo acesso às novas tecnologias e matéria prima. Para a produção artesanal eram necessários recursos como: palha, linha, barbante, madeiras, dentes e ossos de animais, penas, miçangas, sementes, cascas de coco. No entanto, algumas dessas matérias primas ficaram escassas e precisaram ser trocadas ou compradas. Em determinadas situações, era preciso lançar mão de projetos em parceria com organizações governamentais ou ONGs. Acerca disto, K4 esclarece: “Os mais antigos costumavam plantar algodão para fabricar as linhas utilizadas no artesanato. Por praticidade, as linhas são compradas na cidade. As miçangas de várias cores também são compradas ou trocadas entre/com os parentes Kayabi de outras aldeias".

As habilidades destacadas pelos participantes como características de um especialista, foram: (a) habilidades artísticas (artesanato); (b) habilidades linguísticas (língua nativa, a língua portuguesa e a oratória); e (c) habilidades políticas (representação do seu povo junto aos órgãos públicos). Na opinião de dois participantes existiam diferenças na maneira como as habilidades eram reconhecidas em função do tipo e em função do sexo. Com relação ao tipo de talento, para $\mathrm{K} 3$ as pessoas que trabalhavam com artesanato pareciam receber maior atenção do que as que faziam pintura: “As pessoas que fabricam artesanatos são bastante valorizadas. Isto faz parte da valorização da cultura. Há um esforço para resgatar esses valores e também uma busca por novos conhecimentos para aperfeiçoamento”.

As habilidades masculinas estavam mais voltadas para a confecção de artefatos utilizados na caça, pesca e armas de guerra como: arco, flecha, bordunas, cocares e objetos confeccionados com palhas como peneiras, abanos, paneiros e cestos. As mulheres, por sua vez, dedicavam-se aos ornamentos (colares, brincos, anéis e grafismos) e produtos têxteis (redes, tipoias e vestimentas). Maiores detalhes sobre as habilidades e sua divisão por gênero e tipo podem ser visualizados na Tabela 1. 
Tabela 1

Frequência das habilidades por tipo e indicação de gênero $(N=4)$

\begin{tabular}{|c|c|c|c|c|}
\hline Habilidades Reconhecidas & $f$ & $\begin{array}{l}\text { Homens } \\
\text { (f) }\end{array}$ & $\begin{array}{l}\text { Mulheres } \\
\text { (f) }\end{array}$ & $\begin{array}{l}\text { Sem Indicação de } \\
\text { gênero (f) }\end{array}$ \\
\hline Aprendizagem da Língua Matema & 1 & - & - & 1 \\
\hline Contadores de histórias (Anciãos) & 5 & 2 & - & 3 \\
\hline Confecção de Artefatos & 60 & 32 & 28 & \\
\hline Artesanato em geral & 5 & 1 & 4 & - \\
\hline Armas & 12 & 12 & - & - \\
\hline Arco & & 3 & - & - \\
\hline Borduna & & 4 & - & - \\
\hline Flechas & & 5 & - & - \\
\hline Artigos Têxteis & 10 & - & 10 & - \\
\hline Bordados & & - & 1 & - \\
\hline Redes & & - & 5 & \\
\hline Roupas & & - & 1 & - \\
\hline Tapetes & & - & 1 & - \\
\hline Tipoia & & - & 2 & - \\
\hline Utensilios de Palha & 12 & 12 & - & - \\
\hline Abanos & & 5 & - & - \\
\hline Jamanchin(mochila) & & 1 & - & - \\
\hline Paneiros (cesto de vime) & & 1 & - & - \\
\hline Peneiras & & 5 & - & - \\
\hline Omamentos & 21 & 7 & 14 & - \\
\hline Anéis & & - & 1 & - \\
\hline Brincos & & - & 2 & - \\
\hline Cocar & & - & 3 & - \\
\hline Colares & & 7 & - & - \\
\hline Pulseiras & & - & 7 & - \\
\hline Desenho & 1 & - & 1 & - \\
\hline $\begin{array}{l}\text { Domínio da Língua Portuguesa } \\
\text { (Jovens) }\end{array}$ & 1 & - & - & 1 \\
\hline Fogo artesanal & 1 & - & - & 1 \\
\hline Pintura (Grafismo) & 4 & - & 4 & - \\
\hline
\end{tabular}


O artesanato, o desenho e a pintura preservavam os grafismos, a história, os modos de produção Kayabi, mas também sinalizavam a luta e a resistência de manter viva a memória, a identidade e as tradições. A dança e a música possuem uma função ritualística e não artística, sendo utilizada pelos mais velhos por ocasião das festividades. Nesse contexto, também ganham importância os contadores de histórias, como guardiões da memória do povo.

Outra habilidade que parece ser valorizada entre os mais jovens estava relacionada ao domínio da língua portuguesa e da arte da oratória. Esses jovens poderiam ocupar uma importante posição na representação de sua comunidade diante do governo, de autoridades ou de órgãos que atendem a comunidade no sentido de "fazer cumprir os direitos garantidos na legislação no que tange às comunidades indígenas" (K4). Outra habilidade reconhecida na comunidade estava relacionada com o manejo de canoas e de barco a motor. "Saber conduzir um barco a motor em um rio durante o período de cheia e seca, passar por corredeiras $e$ saber onde estão os canais que possibilitam a passagem com segurança é importante" (K4).

\section{Organização Comunitária para o Desenvolvimento dos Talentos}

A riqueza da comunidade, na opinião de dois participantes, estava relacionada aos recursos humanos, ao conhecimento dos mais velhos e à colaboração entre aqueles que são especialistas no estímulo aos mais jovens. Nesta direção, os anciãos eram sempre consultados, contribuindo na formação das novas gerações com informações, técnicas ou provendo recursos materiais e culturais. Esse sentido é evidente no relato de dois participantes: "Como parte da cultura Kayabi: os que têm os saberes repassam o conhecimento para a próxima geração" (K1) e "tentamos contribuir repassando o conhecimento. Não temos recursos específicos. Temos recursos humanos como a experiência dos mais velhos e suas orientações" (K3).

O talento se desenvolve, principalmente, dentro da família vinculada aos afazeres do cotidiano. A família é apontada como a provedora dos recursos necessários para a produção artística. "A família também incentiva os filhos a observarem, aprenderem e dar importância aos talentos e seus feitos" (K3). "A família ajuda e apoia com a provisão de matéria prima: madeira, cipó, tarumã (material para fazer peneira)" (K2). Nesse sentido, K3 ainda complementa: "O apoio dos familiares é muito importante".

Os especialistas, de acordo com os participantes, eram envolvidos com o aperfeiçoamento de suas habilidades e ao ensino de suas técnicas, mesmo com todas as demais rotinas de vida na família e na comunidade (caçam, pescam, cozinham...). Essas 
atividades, no entanto, variavam de acordo com o sexo e as expectativas da comunidade. "Têm rotina normal" (K2). "As mulheres cuidam de suas casas. Vão para a roça com o marido. O homem trabalha normalmente em outras atividades. Eles dedicam um tempo especialmente para fazer os artesanatos e outras artes” (K3). O processo de desenvolvimento do talento é conectado com a dinâmica de vida comunitária, sendo parte da rotina familiar e influenciado pelas demandas da comunidade.

Com relação ao talento das mulheres, $\mathrm{K} 3$, em função de seu ativismo, salienta a necessidade das mulheres perderem o medo e valorizarem seus talentos: "As mulheres, especialmente, precisam perder o medo de se exporem nas reuniões, mostrarem seu talento, sua voz e perder a vergonha de falarem e se apresentarem com a preocupação de não serem aprovadas (...)" . Ainda é observado por K4: "as mulheres sabem pilotar e o fazem quando há muita necessidade, ou seja, quando não têm filhos ou marido que estejam no momento”.

Todos os participantes concordaram com o papel fundamental da Escola Estadual Indígena na disseminação dos saberes e práticas Kayabi. K1 e K2 salientaram a importância da disciplina "Saberes Indígenas" para a disseminação da cultura, das práticas, da alimentação tradicional, das artes corporais, artesanais e tecnologias do Povo Kayabi. K3 e K4 ainda relataram, respectivamente: "A escola tem tentado fazer com que os alunos vejam a importância e desenvolvimento de talentos." E, "atualmente, a escola tem sido um meio de ensinar artesanatos através de aulas práticas. Os especialistas ensinam e os alunos vão reproduzir".

\section{Desafios para o Desenvolvimento dos Talentos: Passado, Presente e Futuro}

Os participantes indígenas reconhecem que no passado havia uma comunhão e troca de experiências mais eficientes entre as gerações. A transmissão oral foi defendida como fator importante para a preservação da cultura: "a cultura indígena é mantida por meio de seus valores passados de geração para geração" (K2). "Elas (as gerações passadas) passaram o conhecimento para aqueles com os quais conviveram e para as novas gerações" (K3).

O processo de desenvolvimento das habilidades e talentos também envolve o aprendizado prático: "Aprende-se a remar, remando; aprende-se a pilotar um barco, pilotando" (K4). Com relação a esse processo, também foi mencionado que os anciãos opinam sobre o que os mais jovens devem aprender e como devem produzir e reproduzir as artes tradicionais. Eles são estimulados desde crianças a observar, imitar e praticar. Com o tempo vão aperfeiçoando as suas habilidades e se tornando respeitados como especialistas. 
Alguns desafios precisam ser superados em relação ao desenvolvimento dos talentos, no ponto de vista dos participantes há demandas no presente que precisam ser atendidas. Entre as quais foram destacadas:

(a) A falta de reconhecimento e valorização dentro da comunidade - Para K2, os especialistas deveriam "receber incentivo para cada vez mais se aperfeiçoarem. O trabalho deles poderia ser mais bem divulgado para além daqueles que estão à sua volta" (K2). Ainda nesse contexto, $\mathrm{K} 3$ acrescenta: "Temos algum reconhecimento fora da comunidade quando somos procurados por pessoas de fora para adquirir os nossos produtos. Gostaríamos muito de reconhecimento e premiações".

(b) A escassez de matéria prima ou falta de recursos financeiros para a obtenção de materiais que não são encontrados na floresta ou mata - "Faltam recursos financeiros para oferecer oficinas de treinamento e outras iniciativas. (...). Encontrar materiais adequados para o trabalho, uma vez que estes nem sempre são encontrados em todos os lugares por uma série de razões como a extinção ou inexistência destes em algumas regiões. Às vezes é arriscado. Algumas tentativas são frustradas" (K1) e “(...) precisamos de muito apoio, pois os recursos são escassos para adquirir o material necessário como miçangas, barbantes, lixas, limas, instrumentos etc." (K3).

(c) um local adequado para o desenvolvimento de suas habilidades e oportunidade para divulgar a produção - "Falta oportunidade para sair da comunidade e mostrar seus talentos na cidade, por exemplo. Deveriam ter recursos para aquisição de materiais, um local adequado para o trabalho e tempo em conjunto exclusivo para o desenvolvimento de habilidades" (K3).

(d) o acesso às tecnologias de informação e comunicação - Na percepção dos participantes, as tecnologias trazem prejuízo para a manutenção das tradições e valores da comunidade Kayabi. Nesta direção, K2 argumenta que ela afeta $o$ "diálogo dos mais velhos com os mais jovens. A tecnologia tem tirado dos jovens o desejo de aprender com os mais velhos. O mundo externo tem sido mais atrativo para os jovens isolando-os dos velhos.”.

\section{Valores a Serem Considerados na Promoção e Atendimento dos Talentos entre os Kayabi}

Foi apontado, ao longo das entrevistas, um conjunto de valores a serem considerados para a formulação de políticas públicas e no planejamento de ações que visem o desenvolvimento dos talentos. O primeiro deles diz respeito à importância da identidade 
cultural. Para os Kayabi, "a cultura é forte e está no cerne de suas mentes, nos relacionamentos, nas expressões culturais, no viver diário em família e na Comunidade" (K4). Ainda com relação a este tópico, “O maior recurso ou riqueza seria a nossa própria língua e cultura. "Não precisamos ser muitos para sermos grandes e valorosos", comentou K3.

O segundo valor vincula-se à preservação dos recursos naturais, para além de uma visão comercial. Nesta perspectiva, esses recursos deveriam ser preservados devido ao seu impacto nos modos de vida dos Kayabi. Esses recursos estão profundamente implicados na maneira como produzem seus alimentos, seus instrumentos e sua arte. Nesse sentido, K3 acrescenta que "a sustentabilidade é um desafio para todos os povos".

$\mathrm{O}$ terceiro aspecto a ser contemplado diz respeito à importância dos saberes ancestrais. Para dois dos participantes (K1 e K2), é necessário que a comunidade encontre meios de fortalecer os saberes por meio do diálogo inter e intra geracional. Sem esse diálogo, não há como preservar a cultura e atender as demandas do futuro.

A não dissociação de unidade e conjunto é expressa em todos os momentos da vida comunitária, desde a alimentação em comum até a transmissão dos saberes. Há um sentido de unidade na coletividade, de forma que não se trata de um indivíduo, mas de um coletivo que se articula, se esforça e se mobiliza. Tudo que é produzido visa atender uma demanda coletiva da comunidade: "o conhecimento resulta na resposta de demandas e soluções práticas para o dia a dia da comunidade e contém informações e traços da cultura” (K1).

Por último, e não menos importante, fica evidente o papel dos especialistas na mentoria e tutoria das crianças e jovens como suporte necessário para o seu desenvolvimento dos talentos entre os Kayabi. De forma que, os processos de identificação e de atendimento devem considerar a atuação desses atores comunitários.

\section{Discussão}

A Educação Escolar Indígena ainda carece de adequações curriculares e formação de professores para o atendimento educacional especializado de crianças e jovens indígenas. Essa situação ainda é mais urgente quando se trata do desenvolvimento e atendimento de talentos. Esses processos, no Brasil, ainda são limitados ao uso de testes psicométricos e ao ambiente escolar, não contemplando a diversidade sociocultural e linguística do nosso país. Esses resultados corroboram outros estudos ao indicarem que o desenvolvimento de talentos em comunidades tradicionais deve incluir a participação de vários atores comunitários no 
processo de identificação, múltiplos instrumentos e procedimentos de construção de dados, oficinas preparatórias e a utilização de vários espaços sociais (Siegle et al., 2016; Vialle, 2011).

Nesta direção, as atividades de enriquecimento escolar se mostram adequadas ao desenvolvimento de talentos em comunidades tradicionais por seu caráter democrático e flexível (Renzulli \& Reis). As atividades de enriquecimento escolar podem ser de três tipos: (1) exploratórias, (2) de treinamento de habilidades e aprimoramento técnico, e (3) de resolução de problemas reais. As atividades exploratórias oportunizam o mapeamento das possibilidades e potencialidades presentes na comunidade. As atividades do tipo 2, seriam uteis na formação continuada de especialistas e para o aumento da eficiência de processos produtivos. As atividades do tipo 3, teriam como protagonistas crianças e jovens Kayabi na busca de solução de problemas de sua comunidade por meio de pesquisa e projetos autênticos.

\section{Considerações Finais}

Os resultados do nosso estudo apontam para a necessidade de que sejam revistos o conceito de superdotação empregado e as estratégias utilizadas nos processos de identificação e avaliação que dão acesso a atendimento educacional especializado de estudantes talentosos. Nesta direção, é relevante considerar a identidade cultural, os saberes ancestrais, a indissociabilidade entre unidade e conjunto, o papel dos especialistas e o aprender prático. A criatividade não está associada a características individuais ou de uma produção inovadora, mas à solução de problemas comunitários e conflitos interpessoais. Os recursos para o desenvolvimento das potencialidades e talentos do povo Kayabi e de outras comunidades tradicionais passam pela preservação do meio ambiente e de seu patrimônio imaterial. Questões que envolvem as novas gerações e toda a sociedade envolvente.

Há um grande desperdício dos talentos no Brasil, contudo esse cenário é ainda mais grave se considerarmos que o extermínio dos povos indígenas tem colocado em risco de extinção boa parte das ciências, das artes, das línguas e da memória do nosso próprio continente. Evitar essa catástrofe implica no planejamento e implementação de múltiplas estratégias intersetoriais que, entre outras prioridades, devem propiciar o atendimento educacional especializado em escolas indígenas. Essas iniciativas devem contribuir para o mapeamento das potencialidades comunitárias, o desenvolvimento dos talentos de crianças e jovens, o desenvolvimento de pesquisas que forneçam indicadores para a elaboração de políticas públicas para a Educação Escolar Indígena - especialmente a formação de 
professores - e a preservação do patrimônio imaterial dessas comunidades. Ainda indicamos para estudos futuros o aprofundamento da concepção de talentos e o entendimento sobre as interrelações entre os processos individuais e coletivos no qual o talento Kayabi emerge e se desenvolve.

\section{Referências}

Alcântara, R. S. (2015). (Re) conhecendo a língua-cultura Kayabi por meio de palavras com carga cultural partilhada (Dissertação de Mestrado). Departamento de Línguas Estrangeiras e Tradução, Programa de Pós-Graduação em Linguística Aplicada, Universidade de Brasília, Brasília, DF. Recuperado de https://repositorio.unb.br/handle/10482/19116

Alencar, E. M. L. S., Braga, N., Prado, R. M., \& Chagas-Ferreira, J. F. (2015). Spirituality and creativity of indigenous societies in Brazil and their legacy to Brazilian culture and creative giftedness. Gifted Education International, 32(3), 224--231. doi: $10.1177 / 0261429415602581$

Athayde, S., Silva-Lugo, J., Schmink, M., Kaiabi, A., \& Heckenberger, M. (2017). Reconnecting art and science for sustainability: Learning from indigenous knowledge through participatory action-research in the Amazon. Ecology and Society, 22(2), 3646. doi: 10.5751/ES-09323-220236

Bampil, A. C., \& Diel, J. O. (2017). Diálogo educador entre indígenas e pedagogos(as) em formação: Uma ponte para compreender e valorizar a diversidade cultural indígena brasileira. Tellus, 17(32), 9-27. doi: 10.20435/tellus.v17i32.424

Becker, M. A., \& Milon, H. F. (2012). Estudos em altas habilidades no Amazonas. Revista AMAzônica, 5(3), 220-257. Recuperado de https://dialnet.unirioja.es/descarga/articulo/4049442.pdf

Becker, M. A., Nino, C. G. R., \& Weigel, N. V. (2009). Pesquisa na área Sateré-Mawé: A descoberta de talentos indígenas. Revista Semestral da Associação Brasileira de Psicologia Escolar e Educacional, 13(1), 55-63. doi: 10.1590/S141385572009000100007

Brasil. (2002). Referencial Curricular Nacional para as Escolas Indígenas. Brasília: MEC/SEF.

Brasil. (2012). Diretrizes Curriculares Nacionais da Educação Escolar Indígena na Educação Básica. Diário Oficial da União, 121(1), 7. 
Breakwell, G. M., Fife-Schaw, C., Hammond, S. M., \& Smith, J. (Eds.). (2010). Métodos de pesquisa em Psicologia (3a ed.). Porto Alegre: Artmed.

Brunet, M. B. (2018, Agosto). Saberes tradicionais indígenas e sustentabilidade: Diálogos na construção do (Etno) desenvolvimento sustentável. In Anais do Seminário Internacional em Ciências do Ambiente e Sustentabilidade na Amazônia (Vol. 5, pp. 1-12). Universidade Federal do Amazonas, Manaus, Amazonas, Brasil. Recuperado de https://even3.blob.core.windows.net/anais/91703.pdf

Carvalho, N. C., \& Ferreira, W. A. A. (2017). Projetos novos talentos: Desafios e contribuições na aldeia indígena Mayrob-Ti Apiaká- Kayabi - Povo Apiaká. Revista de Comunicação Científica, 2(1), 88-99. Recuperado de https://periodicos.unemat.br/index.php/rcc/article/view/2229

Ferreira, W. A. C. (2014). Educação escolar indígena na terra indígena Apiaká-Kayabi em Juara - MT: Resistências e desafios (Tese de Doutorado). Programa de PósGraduação em Educação, Universidade Federal do Rio Grande do Sul, Porto Alegre, RS, Brasil. Recuperado de https://lume.ufrgs.br/handle/10183/87960

González-Rey, F. L. (2011). Pesquisa qualitativa em psicologia: Caminhos e desafios. São Paulo: Cengage Learning.

Guimarães, R. (2017). Kayabi: Cantos e grafismos. Campinas, SP: Gaia Social.

Lima, A., \& Sato, M. (2011). Educação Kayabi: Um diálogo entre o currículo e os projetos de sustentabilidade nas aldeias. Revista Terceiro Incluído, 1(2), 1-21. doi: 10.5216/teri.v1i2.16769

Mori, A. G., Cruz, M. C., \& Quintino, W. P. (2017). Políticas linguísticas no curso de licenciatura intercultural da UNEMAT: Manutenção e fortalecimento das línguas indígenas. Revista de Educação Pública, 26(62/2), 569-582. doi: 10.29286/rep.v26i62/2.5499

Oliveira, F. C. B. (2017). Ecological relations are affective relations: The Xinguan Kaiabi and the proximity with the Teles Pires River (southeastern Amazonia, Brazil). Canadian Journal of Latin American and Caribbean Studies, 42(2), 125-143. doi: $10.1080 / 08263663.2017 .1330732$

Pagliaro, H. (2010). A recuperação demográfica dos povos indígenas do Brasil: A experiência dos Kayabi do Parque Indígena do Xingu - Mato Grosso. Cadernos de Saúde Pública, 26(3), 579-590. Recuperado de http://www.abep.org.br/publicacoes/index.php/anais/article/view/1239/1203 
Renzulli, J., \& Reis, S. (2014). Schoolwide Enrichment Model (3a ed.). Mansfield, CT: Prufock Press.

Siegle, D., Gubbins, J. E., O’Rouke, P., Langley, S. D., Mun, R. U., Luria, S. R., . . Plucker, J. A. (2016). Barriers to underserved students' participation in gifted programs and possible solutions. Journal for the Education of the Gifted, 39(2), 103-131. doi: $10.1177 / 0162353216640930$

Silva, W. M., \& Ferreira, W. A. A. (2016). Currículo agroecológico na Escola Estadual Juporijup-povo Kayabi: Educação escolar indígena latino-americana. Revista de Comunicação Científica da Universidade do Estado do Mato Grosso, 1(1), 16-29. Recuperado de https://periodicos.unemat.br/index.php/rcc/article/view/1390/1371

Sternberg, R. J., Jarvin, L., \& Grigorenko, E. L. (2011). Explorations in Giftedness. New York, NY: Cambridge University Press.

Vialle, W. (2011). (Eds.). Giftedness from an Indigenous Perspective. Melbourne: AAEGT/University Wollongong Printery.

Weschler, S. M., \& Fleith, D. S. The scenario of gifted education in Brazil. Congent Education, 4(1), 1-12. doi: 10.1080/2331186X.2017.1332812

\section{Endereço para correspondência}

\section{Jane Farias Chagas-Ferreira}

Universidade de Brasília

Departamento de Psicologia Escolar e do Desenvolvimento

SGAN - Campus Darcy Ribeiro, Brasília - DF, Brasil. CEP 70297-400

Endereço eletrônico: janefcha@gmail.com

Recebido em: 11/03/2020

Reformulado em: 24/08/2020

Aceito em: 31/08/2020

\section{Notas}

* Professora da Universidade de Brasília, vinculada ao Instituto de Psicologia, Departamento de Psicologia Escolar e do Desenvolvimento.

Financiamento: a pesquisa relatada no manuscrito foi financiada pela Fundação de Apoio à Pesquisa do Distrito Federal - FAPDF em projeto de posdoutoramento realizado no Renzulli Center for Creativity, Gifted Education and Talent Development, University of Connecticut. 
Agradecimento: a autora agradece a Ana Gabriela Mauch, Carlos Alcântara e Raquel Alcântara pelo apoio na coleta de dados e pela letura de uma das versões preliminares deste manuscrito.

Este artigo de revista Estudos e Pesquisas em Psicologia é licenciado sob uma Licença Creative Commons Atribuição-Não Comercial 3.0 Não Adaptada. 